\title{
Effects of lacidipine on peak oxygen consumption, neurohormones and invasive haemodynamics in patients with mild to moderate chronic heart failure
}

R J M de Vries, P H J M Dunselman, U G Chin Kon Sung, D J van Veldhuisen, H M A Corbeij, W H van Gilst, K I Lie

\begin{abstract}
Objective-To evaluate the efficacy and safety of the second generation dihydropyridine calcium channel blocker lacidipine in patients with heart failure.

Design-Placebo controlled, parallel group, double blind study over 8 weeks.

Setting-General community hospital in Breda, The Netherlands.

Patients-A random sample was studied of 25 outpatients with symptoms of mild to moderate heart failure, despite treatment with diuretics, digoxin, and angiotensin converting enzyme inhibitors. Their mean age was 65 years, with mean left ventricular ejection fraction of 0.24 and a peak oxygen consumption of $14.4 \mathrm{ml} / \mathrm{min} / \mathrm{kg}$. Two patients dropped out on lacidipine, one patient on placebo.

Intervention-Treatment with lacidipine $4 \mathrm{mg}$ once daily or placebo for eight weeks.

Main outcome measure-Cardiopulmonary exercise testing, invasive haemodynamics, and plasma neurohormones.

Results-Treatment with lacidipine $4 \mathrm{mg}$ once daily, as compared to placebo treatment, significantly improved peak oxygen consumption $(P<0.02)$, cardiac index $(P$ $<0.01)$, and stroke volume $(P<0.03)$ paralleled by a decrease in systemic vascular resistance $(P<0.03)$ and arteriovenous oxygen content difference $(P<0.01)$. Plasma noradrenaline, plasma renin activity, and aldosterone values did not differ between lacidipine and placebo.
\end{abstract}

Fixed dose ACE + diuretics + digitalis

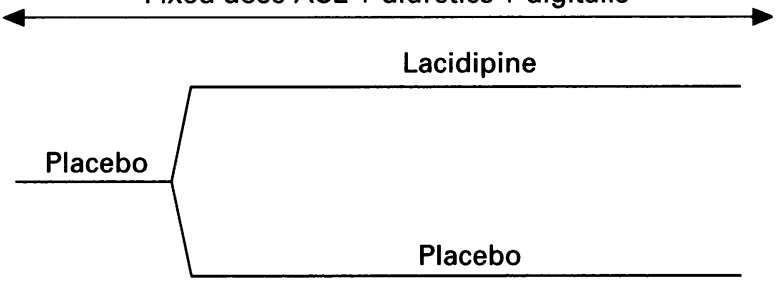

$\begin{array}{lllllll}\text { Week } & -2 & 0 & 2 & 4 & 6 & 8 \\ \begin{array}{l}\text { History/examination } \\ \text { Electrocardiogram }\end{array} & \mathrm{X} & \mathrm{X} & \mathrm{X} & \mathrm{X} & \mathrm{X} & \times \\ \begin{array}{l}\text { Invasive haemodynamics } \\ \text { MUGAVechocardiography }\end{array} & \mathrm{X} & & & & \times \\ \begin{array}{l}\text { CPX } \\ \text { Neurohormones }\end{array} & \mathrm{X} & & & & \times \\ \text { X } & \mathrm{X} & & & & \times \\ \end{array}$

Figure 1 Study design. ACE, angiotensin coverting enzyme inhibitor; CPX, cardiopulmonary exercise test (bicycle); MUGA, multiple gated radionuclide cardiopulmonary
Conclusions-This second generation dihydropyridine may be of value as an adjunct to standard treatment in congestive heart failure patients.

(Heart 1996;75:159-164)

Keywords: congestive heart failure; lacidipine; peak oxygen consumption; neurohormones.

Chronic heart failure is a major public health problem. Despite angiotensin converting enzyme inhibitors, digoxin, and diuretics, both mortality and morbidity remain high. ${ }^{1}$ There is a compelling need for therapeutic alternatives or additives. ${ }^{2}$

The direct arterial vasodilator effect of the dihydropyridine calcium channel blockers results in a reduction of systemic vascular resistance. This may be beneficial as an adjunct to the indirect vasodilating angiotensin converting enzyme inhibitors. However, vasodilatation-induced neurohumoral activation and negative inotropic effects of the first generation of these dihydropyridines resulted in a disappointing outcome in heart failure studies. ${ }^{34}$ In recent years more selective dihydropyridine calcium antagonists have been developed, typified by a slow onset of action, a long plasma half life, and a narrow trough to peak ratio. This may result in less neurohormonal activation, while high vascular selectivity may lead to less negative inotropic effects. Lacidipine is one such new dihydropyridine derived vascular selective calcium antagonist with a slow onset and longer duration of action, ${ }^{5}$ which has been proven effective as an antihypertensive agent. ${ }^{67}$

This study, which is the first using lacidipine in heart failure patients, was designed to explore the efficacy and safety of lacidipine when given in conjunction with angiotensin converting enzyme inhibitors, digoxin, and diuretics.

\section{Methods}

STUDY DESIGN

The study was a prospective, double blind, randomised, placebo controlled, parallel group comparison (fig 1), performed in one centre (Ignatius Hospital, Breda). During a single blind, placebo run in period of 7-14 days clinical stability was confirmed and patient characteristics were obtained. Clinical stability was defined as unchanged New York Heart 
Association classification, unchanged drug treatment, and reproducibility of the cardiopulmonary exercise tests. If a patient fulfilled all entry criteria at the end of this period he was eligible for the double blind treatment period with lacidipine $4 \mathrm{mg}$ once daily or placebo. At baseline, echocardiography, plasma neurohormones, and invasive haemodynamic indices were obtained. During the study, patients were seen every two weeks in the outpatient department where a complete cardiovascular examination was performed and New York Heart Association class and adverse effects were evaluated. Adherence to study medication was checked by pill count. After eight weeks the clinical and haemodynamic evaluations were repeated, and a subjective assessment of general improvement or deterioration was made both by investigator and patient. The protocol was approved by the ethics committee of the Ignatius Hospital Breda and was conducted in accordance with the revised Declaration of Helsinki. Before the study, all patients gave informed, written consent.

\section{PATIENTS}

Patients were included in this study if they fulfilled the following entry criteria: (A) age $>18$ years; (B) stable heart failure (New York Heart Association class II-III), while on fixed medication (for at least six weeks) of angiotensin converting enzyme inhibitors (enalapril > $10 \mathrm{mg}$ or captopril $>75 \mathrm{mg}$ daily), digoxin and diuretics; (C) left ventricular ejection fraction $<0.40$ as assessed by radionuclide ventriculography; (D) cardiothoracic ratio $>0.52$ on chest $x$ ray or left ventricular end diastolic diameter $>5.5 \mathrm{~cm}$ by echocardiography; (E) reproducible and valid cardiopulmonary exercise test, which was limited by dyspnoea or fatigue, with a peak oxygen consumption $>10$ and $<20 \mathrm{ml} / \mathrm{kg} / \mathrm{min}$.

Exclusion criteria included active myocarditis, obstructive cardiomyopathy, aortic stenosis or insufficiency, hypotension (systolic blood pressure $<105 \mathrm{~mm} \mathrm{Hg}$ ), myocardial infarction, coronary angioplasty or cardiac surgery (all within two months), ventricular demand pacemaker, symptomatic arrhythmia, atrial fibrillation or flutter with a ventricular response $>100$ beats $/ \mathrm{min}$, supraventricular tachycardia $>120$ beats $/ \mathrm{min}$, severe obstructive pulmonary disease, relevant hepatic, haematological or renal disease, phaeochromocytoma, psychiatric illness, and known intolerance of the study drug.

\section{CARDIOPULMONARY EXERCISE TEST}

Exercise testing with respiratory gas exchange was performed 1-3 h after intake of study medication, while patients exercised on a electronically braked bicycle ergometer (Erich Jaeger). The exercise protocol started at a workload of $20 \mathrm{~W}$, with increments every 2 min by $20 \mathrm{~W}$ up to appearance of limiting dyspnoea or fatigue. Patients breathed through a mask into a mixing bag. ${ }^{8}$ Oxygen consumption, carbon dioxide production, and respiratory exchange ratios were measured continuously using an automated gas exchange measuring system (EOS sprint version 4.01, Erich Jaeger). All patients were familiar with the cardiopulmonary exercise test. Values were recorded at $30 \mathrm{~s}$ intervals. Heart rate and blood pressure, measured with a mercury sphygmomanometer, were recorded before, after every other minute during, at peak, and at 2 and $5 \mathrm{~min}$ after exercise. The electrocardiogram was monitored (Siemens Mingograf 410) using a bipolar lead system. Reasons for discontinuation of the exercise test during the double blind period were: symptom limited dyspnoea, fatigue or chest discomfort, severe or sustained (supra)ventricular arrhythmias, fall of $>20 \mathrm{~mm} \mathrm{Hg}$ in systolic blood pressure during exercise, and increase in systolic blood pressure of $>250$ $\mathrm{mm} \mathrm{Hg}$. Maximum achieved workload was defined as the maximum workload maintained for at least $30 \mathrm{~s}$. Highest comparable submaximal workload was defined as the highest workload level below maximum achieved workload that was completed both at baseline and after eight weeks. Thus if maximum workload at one test is $120 \mathrm{~W}$ and at the other test $100 \mathrm{~W}$, the highest comparable submaximal workload is $80 \mathrm{~W}$. The exercise test was considered reproducible if the duration of the second test during the run in period varied by $<2 \mathrm{~min}$ from the first exercise test; an exercise test was considered valid if the ventilatory exchange ratio increased during exercise with at least $0 \cdot 15$ or to an absolute value $>1 .^{8}$

\section{INVASIVE HAEMODYNAMICS}

Patients were studied in supine position, after an overnight fast. A $7.5 \mathrm{~F}$, triple lumen, pulmonary artery catheter with a fast thermistor (model 93A-431H, Edward's Laboratories) was introduced through a subclavian vein and positioned in the pulmonary artery. Brachial arterial blood pressure was measured with a thin walled gauge sheath (Arrow R20). Blood pressures were continuously recorded with Statham P231D pressure transducers positioned at mid-heart level, and registered on a multichannel recorder (Elema 803). Mean blood pressures were obtained by electronic integration of the phasic pressure tracing. The electrocardiogram was monitored throughout the study. Cardiac output and right ventricular ejection fraction were determined by the thermodilution technique, using an Edward's cardiac output computer (REF-1, Edwards Laboratories), with $10 \mathrm{ml}$ of cold dextrose $5 \%$ and in-line sensing of the injectate temperature. The average value of seven successive measurements was accepted if they varied by $<10 \%$. Arterial and mixed venous (pulmonary) blood samples were drawn and analysed for $\mathrm{O}_{2}$ saturation (Instrumentation Laboratories 282). The following haemodynamic variables were recorded: heart rate, systemic and pulmonary arterial and venous pressures, arterial and mixed venous oxygen saturation, right atrial pressure, pulmonary capillary wedge pressure, cardiac output, and right ventricular ejection fraction. Cardiac index, systemic vascular resistance, stroke volume, and arteriovenous oxygen content differ- 
ence were calculated. The assessments were made two to three hours after the intake of the study medication.

\section{ASSESSMENT OF LEFT VENTRICULAR FUNCTION AT REST}

Left ventricular ejection fraction was obtained from the radionuclide ventriculography (multiple gated equilibrium technique ${ }^{9}$ ). From the echocardiogram left ventricular end diastolic and end systolic diameters were obtained to calculate shortening fraction.

\section{PLASMA NEUROHUMORAL INDICES}

Blood for neurohumoral determinations was drawn after $30 \mathrm{~min}$ of supine rest, immediately centrifuged, and the plasma was frozen at $-20^{\circ} \mathrm{C}$. Analysis of plasma noradrenaline and aldosterone was done using a sensitive high performance liquid chromatography assay with electrochemical detection. ${ }^{10}$ Plasma renin activity was measured by radioimmunoassay (Dupont, Ria NEN kit No NEA-022, 026).

\section{STATISTICAL METHODS}

Indices of primary efficacy were the results of cardiopulmonary exercise tests: oxygen consumption, exercise time, and rate-pressure product ( $=$ systolic blood pressure $\times$ heart rate) at maximum achieved workload and at highest comparable submaximal workload. Secondary efficacy indices were the results from haemodynamic investigations and effects on plasma neurohormones. Safety indices consisted of effects on echocardiography variables, electrocardiogram, blood tests, and clinical events.

Comparisons were made with Student's $t$ test for normal distribution or with Wilcoxon two sample rank-sum test in case of abnormal

Table 1 Baseline demographic, clinical, neurohumoral, and haemodynamic characteristics. Values given are number of patients, and means (SD).

\begin{tabular}{|c|c|c|}
\hline & \multicolumn{2}{|l|}{ Medication } \\
\hline & Lacidipine $(n=12)$ & Placebo $(n=13)$ \\
\hline Age (years) & $62(11)$ & $68(10)$ \\
\hline Sex (male/female) & $12 / 0$ & $10 / 3$ \\
\hline Height $(\mathrm{cm})$ & $175(7)$ & $168(7)$ \\
\hline Weight (kg) & $79(10)$ & $75(15)$ \\
\hline \multicolumn{3}{|l|}{ Aetiology of heart failure (n) } \\
\hline Ischaemic heart disease & 11 & 12 \\
\hline Hypertension & 1 & 0 \\
\hline Idiopathic cardiomyopathy & 0 & 1 \\
\hline \multicolumn{3}{|l|}{ New York Heart Association functional class } \\
\hline$(\mathrm{II} / \mathrm{III})(\mathrm{n})$ & $8 / 4$ & $9 / 4$ \\
\hline Previous myocardial infarct $(\mathrm{n})$ & 11 & 11 \\
\hline Diabetes mellitus (n) & & \\
\hline Left ventricular ejection fraction & $0.21(0.08)$ & $0.26(0.08)$ \\
\hline \multicolumn{3}{|l|}{ Echocardiographic indices } \\
\hline Left ventricular end diastolic diameter $(\mathrm{mm})$ & $71(9)$ & $62(6)$ \\
\hline Left ventricular end systolic diameter (mm) & $58(9)$ & $51(8)$ \\
\hline Shortening fraction & $0.18(0.03)$ & $0.21(0.05)$ \\
\hline \multicolumn{3}{|l|}{ Invasive haemodynamic variables } \\
\hline Mean arterial blood pressure $(\mathrm{mm} \mathrm{Hg})$ & $115(22)$ & $104(16)$ \\
\hline Heart rate (beats/min) & $75(14)$ & 74 (14) \\
\hline Pulmonary artery pressure $(\mathrm{mm} \mathrm{Hg})$ & $24(8)$ & $20(7)$ \\
\hline Pulmonary capillary wedge pressure $(\mathrm{mm} \mathrm{Hg})$ & $14(8)$ & $12(6)$ \\
\hline Right atrial pressure ( $\mathrm{mm} \mathrm{Hg}$ ) & $1.0(1.5)$ & $2 \cdot 4(2 \cdot 1)$ \\
\hline Cardiac index (litre $/ \mathrm{min} / \mathrm{m}^{2}$ ) & $2 \cdot 84(0.64)$ & $2.64(0.67)$ \\
\hline Stroke volume $(\mathrm{ml} / \mathrm{beat} / \mathrm{min})$ & $75(20)$ & $69(21)$ \\
\hline Right ventricular ejection fraction & $0.35(0.12)$ & $0.36(0.08)$ \\
\hline Systemic vascular resistance $\left(\mathrm{dyn} \cdot \mathrm{s} \cdot \mathrm{cm}^{-5}\right)$ & $1702(338)$ & $1757(507)$ \\
\hline Pulmonary vascular resistance $\left(\mathrm{dyn} \cdot \mathrm{s} \cdot \mathrm{cm}^{-5}\right)$ & $166(98)$ & $165(141)$ \\
\hline $\begin{array}{l}\text { Arteriovenous oxygen content difference } \\
\left(\mathrm{ml} \mathrm{O}_{2} / 100 \mathrm{ml}\right)\end{array}$ & $5.6(0.9)$ & $5.8(1.5)$ \\
\hline \multicolumn{3}{|l|}{ Neurohormones } \\
\hline Noradrenaline $(\mathrm{pg} / \mathrm{ml})$ & $677(313)$ & $891(545)$ \\
\hline Renin activity $(\mathrm{ng} / \mathrm{ml} / \mathrm{h})$ & $19(15)$ & $23(26)$ \\
\hline Aldosterone $(\mathrm{pmol} / \mathrm{ml})$ & $0.48(0.35)$ & $0.46(0.60)$ \\
\hline
\end{tabular}

distribution or ordinal response data. Mean differences between the treatments, with their standard deviations, are given unless indicated otherwise. All $\mathrm{P}$ values reported are for two tailed tests, and a $P$ value $<0.05$ was considered statistically significant.

\section{Results}

PATIENTS

Twenty five patients entered the study. Baseline characteristics are presented in table 1 . There were no significant differences between the groups at baseline. Before unblinding of the trial code three patients were excluded from the efficacy analysis as they had not all had their final assessments performed according to the protocol; one patient (placebo) had a cerebrovascular accident caused by a cerebral tumour; one lacidipine patient had a lung metastasis of a Grawitz tumour (unknown at the time of inclusion); one patient (lacidipine) experienced worsening heart failure necessitating hospital admission. The remaining 22 patients form the study population for the efficacy indices: 12 were randomised to placebo and 10 to lacidipine. For peak oxygen consumption two additional analyses were performed with inclusion of the lacidipine patient who had been admitted to hospital with worsening heart failure. In the first analysis for peak oxygen consumption at the final visit this patient's baseline peak oxygen value was used (that is, no change); in the second analysis the worst recorded value for peak oxygen consumption was taken.

CARDIOPULMONARY EXERCISE TEST

Peak oxygen consumption increased by 1.3 $\mathrm{ml} / \mathrm{min} / \mathrm{kg}$ to 16.1 (SD 3.4) with lacidipine and decreased by $0.6 \mathrm{ml} / \mathrm{min} / \mathrm{kg}$ to $13.6(2 \cdot 2)$ with placebo $\quad(\mathrm{P}<0.02$ between treatments, fig 2). The two additional analyses revealed similar results with $P$ values of 0.02 and 0.06 respectively. Exercise duration increased by $28 \mathrm{~s}$ to 538 (215) s with lacidipine, and decreased by $4 \mathrm{~s}$ to $486(145) \mathrm{s}$ with placebo (P $=$ NS). At rest, submaximal and peak exercise, heart rate, and blood pressure remained unchanged (table 2).

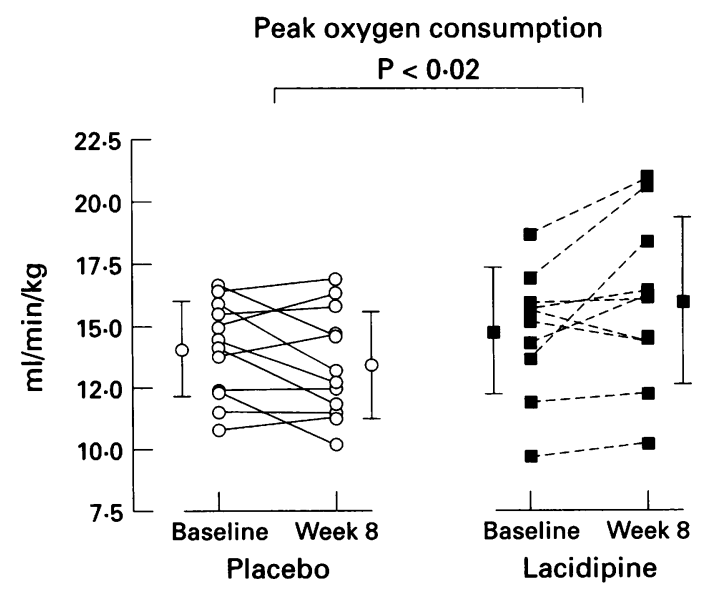

Figure 2 Individual and mean (bars $=S D$ ) peak oxygen consumption at baseline and after eight weeks of placebo treatment (left) and lacidipine treatment (right). 
Table 2 Changes in bicycle cardiopulmonary exercise test indices compared with baseline. Values are means with the $95 \%$ confidence intervals given in parentheses

\begin{tabular}{|c|c|c|c|c|c|c|}
\hline & \multicolumn{2}{|l|}{ Rest } & \multicolumn{2}{|l|}{ Submaximal level } & \multicolumn{2}{|l|}{ Peak exercise } \\
\hline & Lacidipine & Placebo & Lacidipine & Placebo & Lacidipine & Placebo \\
\hline $\begin{array}{l}\text { Rate-pressure product } \\
\text { (mm Hg } \times \text { beats } / \mathrm{min}) \\
\text { Mean arterial blood }\end{array}$ & $-2(-7,3)$ & $-7(-15,1)$ & $-1367(-3407,673)$ & $-538(-2688,1610)$ & $136(-2193,2465)$ & $53(-1838,1945)$ \\
\hline $\begin{array}{l}\text { pressure (mm Hg) } \\
\text { Oxygen consumption }\end{array}$ & $-7(-14,0)$ & $-5(-12,1)$ & $-1(-7,5)$ & $1(-8,9)$ & $3(-2,19)$ & $3(-6,12)$ \\
\hline $\begin{array}{l}\quad(\mathrm{ml} \mathrm{O} / \mathrm{min} / \mathrm{kg}) \\
\text { Respiratory quotient } \\
\text { Exercise time (s) }\end{array}$ & $\begin{array}{l}-0.2(-0.5,0.3) \\
0.01(-0.03,0.04)\end{array}$ & $\begin{array}{l}0.1(-0.5,0.4) \\
0.02(-0.03,0.04)\end{array}$ & $\begin{array}{l}0 \cdot 2(-1 \cdot 1,1 \cdot 5) \\
-0.03(-0 \cdot 10,0.04)\end{array}$ & $\begin{array}{l}-0.6(-1 \cdot 4,0 \cdot 2) \\
-0.01(-0.05,0.04)\end{array}$ & $\begin{array}{l}1 \cdot 3(-0 \cdot 1,2 \cdot 6) \\
-0 \cdot 04(-0 \cdot 09,0 \cdot 01) \\
28(-42,100)\end{array}$ & $\begin{array}{l}-0 \cdot 6(-1 \cdot 5,0 \cdot 3)^{\star} \\
0 \cdot 01(-0 \cdot 06,0 \cdot 05) \\
-4(-21,24)\end{array}$ \\
\hline
\end{tabular}

$\star \mathrm{P}<0.02$ lacidipine $v$ placebo.

Placebo

Lacidipine

Noradrenaline
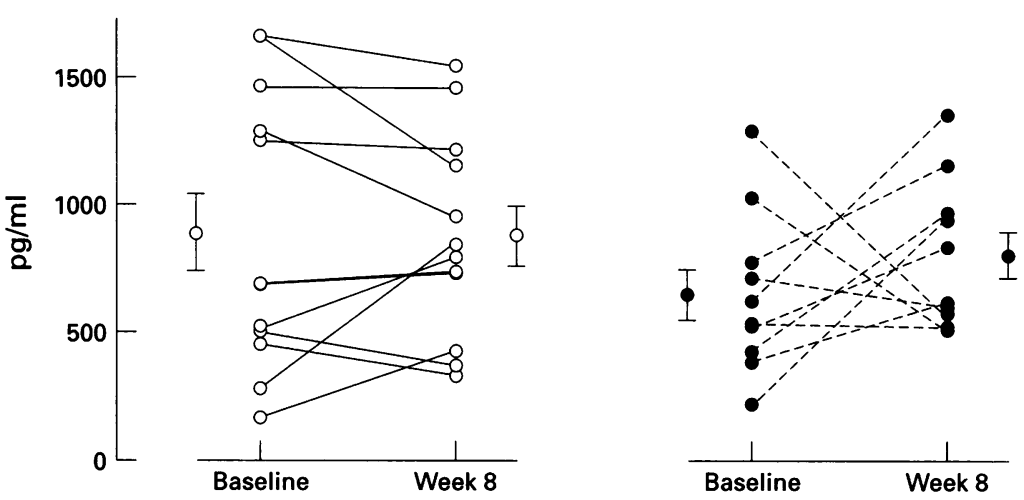

Plasma renin activity
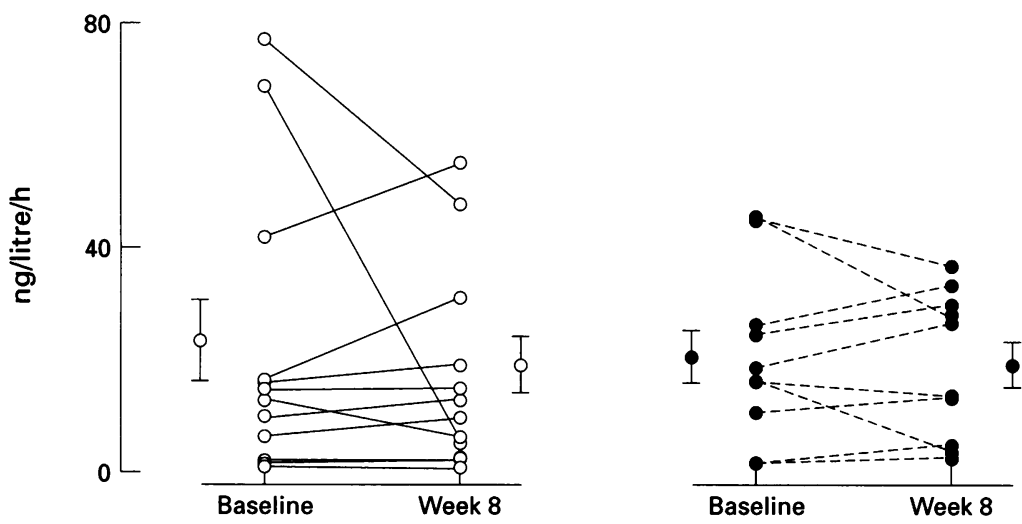

Aldosterone
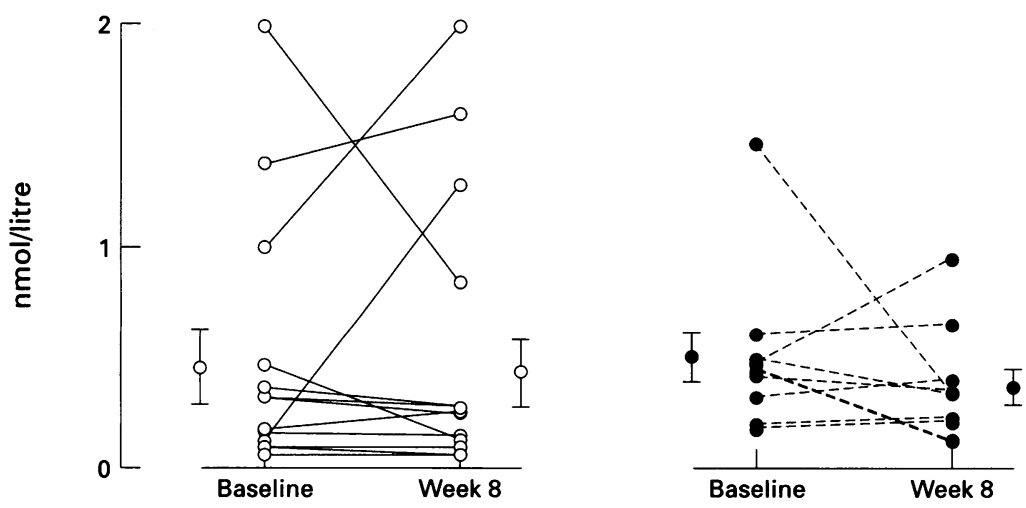

Figure 3 Individual and mean (bars $=S E M$ ) neurohumoral variables at baseline and after eight weeks of placebo treatment (left) and lacidipine treatment (right). No statistical changes are observed within or between groups.
NEUROHUMORAL DATA

The individual values of neurohormones are shown in fig 3. Analysis revealed no statistically significant differences, but standard deviation was large.

\section{HAEMODYNAMICS}

Baseline haemodynamic data were comparable between both groups. After eight weeks of treatment, lacidipine, compared to placebo treatment and own baseline values, significantly reduced systemic vascular resistance by $302 \mathrm{dyn} \cdot \mathrm{s} \cdot \mathrm{cm}^{-5}$ to 1368 (412), pulmonary vascular resistance by $18 \mathrm{dyn} \cdot \mathrm{s}^{\cdot} \mathrm{cm}^{-5}$ to $143(113)$, and arteriovenous oxygen content difference by $0.85 \mathrm{ml} \mathrm{O}_{2} / 100 \mathrm{ml}$ to $4.65 \quad(1.26)$. Lacidipine significantly increased cardiac index by $0.61 \cdot \mathrm{min}^{-1} \cdot \mathrm{m}^{-2}$ to $3.5(1 \cdot 1$ ) (fig 4$)$. No significant changes between treatments were seen for arterial pressures, heart rate, pulmonary artery pressures, pulmonary capillary wedge pressure, right atrial pressure, right ventricular ejection fraction, or pulmonary vascular resistance. Placebo treatment did not change any of the haemodynamic variables.

\section{RADIONUCLIDE VENTRICULOGRAPHY AND} ECHOCARDIOGRAPHY

Left ventricular ejection fraction, left ventricular end diastolic diameter, end systolic diameters, and shortening fraction did not change after treatment.

SIGNS AND SYMPTOMS OF HEART FAILURE

On lacidipine four patients improved clinically by one New York Heart Association class, six noted no change, and one experienced deterioration by one class. In the placebo group two patients improved and 10 experienced no change (NS). During the study one lacidipine patient was given additional glyceryl trinitrate and one patient was admitted to hospital. No other interventions or changes in medication were needed.

\section{SAFETY ANALYSIS}

Of the 25 patients studied, adverse events were reported by seven $(60 \%)$ on lacidipine and four $(31 \%)$ on placebo (NS). Neither treatment affected sitting to standing blood pressures. Serious adverse events were reported in three patients: one on placebo (cerebrovascular accident) and two on lacidipine (lung tumour and worsening of heart failure). There were no deaths during the study. Adherence to study medication was $>95 \%$ in all patients, as estimated by pill count. Results 

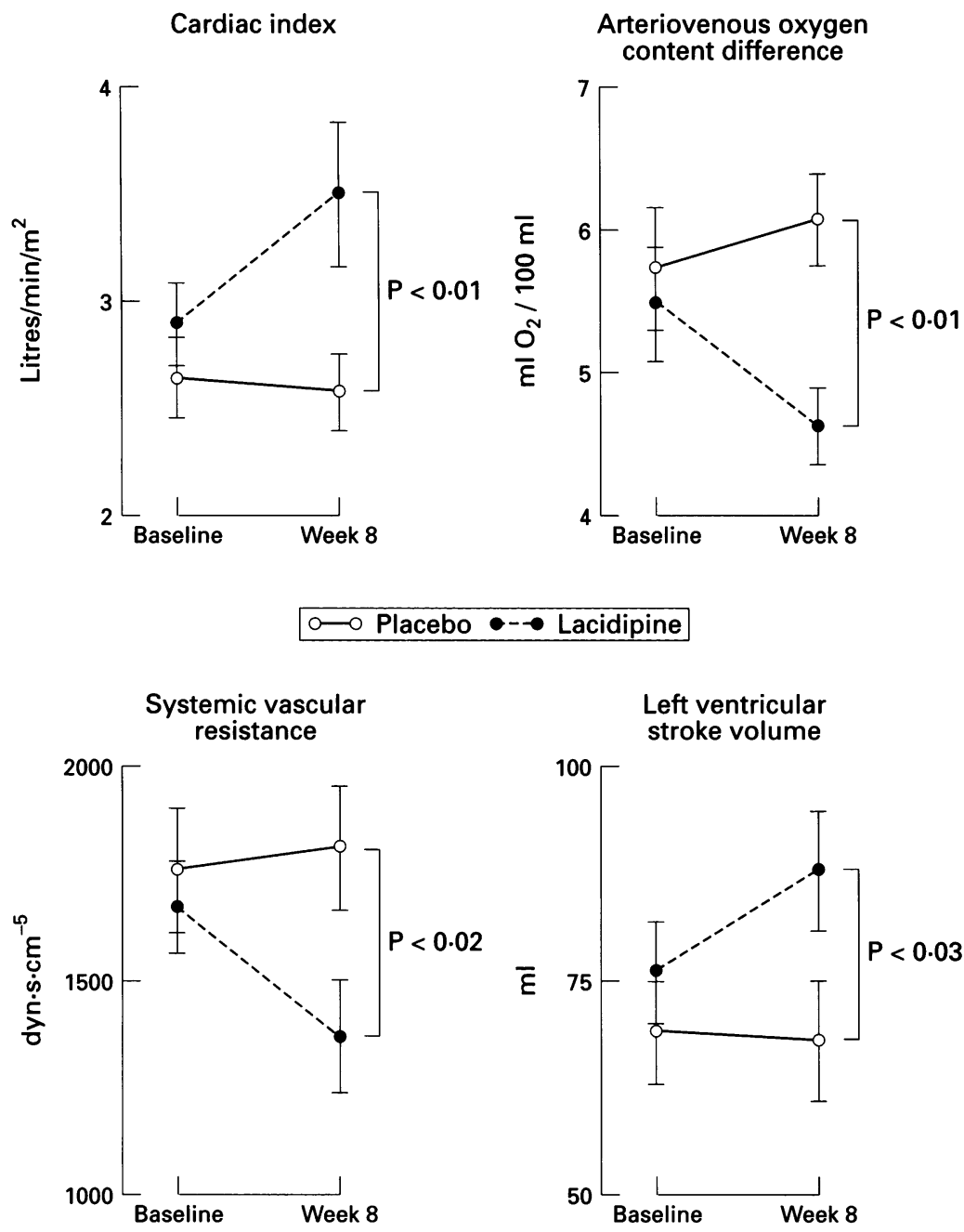

$\rightarrow$ Lacidipine

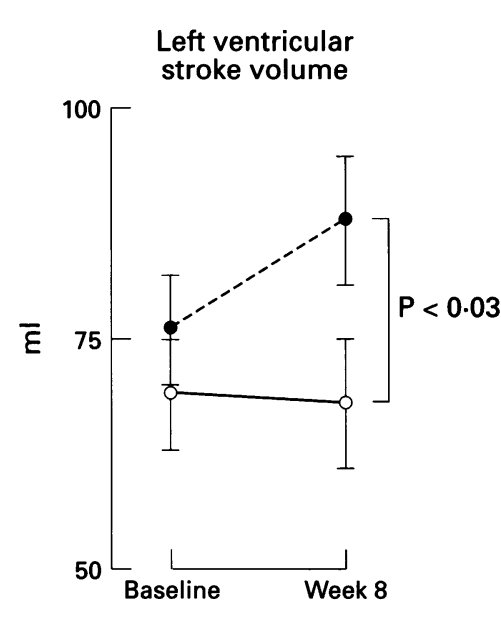

Figure 4 Mean (SEM) invasive haemodynamic variables at baseline and after eight weeks of placebo treatment (empty circles) and lacidipine treatment (filled circles).

from the electrocardiogram, laboratory analyses, and physical examination were not significantly affected during the study.

\section{Discussion}

This exploratory study, the first using the new dihydropyridine calcium channel blocker lacidipine in patients with heart failure, shows that eight weeks of treatment with $4 \mathrm{mg}$ lacidipine, given in conjunction with angiotensin converting enzyme inhibitors, digoxin, and diuretics, increases peak oxygen consumption during exercise and cardiac index at rest. These changes were accompanied by a decrease in systemic vascular resistance without change in arterial blood pressure in these normotensive heart failure patients. The observed changes in neurohumoral indices showed a wide variation but were not statistically different from placebo. Lacidipine did not induce orthostatic hypotension and was well tolerated overall although one lacidipine patient was admitted to hospital for worsening heart failure.

The baseline peak oxygen uptake of 14.4 $\mathrm{ml} / \mathrm{min} / \mathrm{kg}$ indicated impaired aerobic capacity. ${ }^{11}$ The small increase in peak oxygen consumption after eight weeks of treatment with lacidipine, together with an increase in cardiac index and decrease in arteriovenous oxygen content difference without changes in arterial oxygen content, suggests that the observed increase in flow is not shunted to different vascular beds but directed to oxygen consuming body areas in need of increased flow, such as skeletal muscles.

Other studies $^{12-14}$ with second generation dihydropyridines (felodipine, amlodipine, nisoldipine) in heart failure patients have shown conflicting results. Kassis and Amtorp ${ }^{12}$ found an improvement in haemodynamic variables and neurohormones after felodipine. Amlodipine $^{13}$ decreased neurohormonal activation and prolonged exercise duration. Nisoldipine improved clinical status and did not influence neurohormones; however, the initial effects on haemodynamic variables disappeared after three months. ${ }^{14}$ Dunselman et $a l^{15}$ found an improvement in haemodynamics and in exercise duration after eight weeks of treatment with felodipine. Tan $e t a l^{16}$ reported an improvement in haemodynamic variables with felodipine, but no improvement in clinical condition or exercise capacity after three weeks. Nicardipine resulted in worsening of heart failure and neurohumoral activation after four months of treatment. ${ }^{13}$ Apart from lack of uniformity in design and methodology of these studies, it is important to realise that no two dihydropyridines are the same, and that the differences in vasoselectivity, plasma half life, and peak to trough plasma level ratio may partly explain the observed differences in study results.

A cautious approach to our results with lacidipine on neurohumoral activation is justified as this was a small study. However, there are several possible explanations for the lack of overt neurohumoral activation despite pronounced arterial vasodilatation observed in our study and others. First, it may be caused by the increase in cardiac output which may be sufficient to compensate for the decrease in blood pressure, thereby abolishing the need for a heightened compensatory neurohumoral mechanism. If this explanation is true one should have expected the same results with other vasodilators like hydralazine which also result in a significant increase in cardiac output, though associated with neurohumoral activation. Second, the confounding effects of comedication have to be considered as a possible source of the observed beneficial effects of lacidipine in our study. Effects of both angiotensin converting enzyme inhibitors and digoxin in heart failure patients may be partly related to their effect on neurohumoral mechanisms, decreasing the activation of the sympathetic nervous system and the reninangiotensin axis, ${ }^{18-20}$ thereby neutralising or obscuring a possible neurohumoral activation of dihydropyridines. Third, resetting of baroreceptor sensitivity by dihydropyridines, resulting in less sympathetic activation, may play a role. ${ }^{17}$ Finally, the pharmacokinetic profile of this new dihydropyridine, typified by a slow onset of action, longer duration of action, and narrow trough to peak variability, may attribute to this effect.

Although haemodynamic and exercise vari- 
ables improved significantly, no changes in left ventricular systolic function at rest were found. Ejection fraction is a strong prognostic marker in heart failure patients ${ }^{21}$ but our findings may underline the fact that for evaluation of drug induced haemodynamic changes in a small patient group, this non-invasive assessment lacks sensitivity. ${ }^{22}{ }^{23}$ However, the lack of change in left and right ejection fractions and shortening fraction suggests that lacidipine treatment did not result in a deterioration of systolic function, as described with the first generation of dihydropyridines. ${ }^{2425}$

\section{STUDY LIMITATIONS}

The number of patients studied was small and therefore the data must be interpreted with caution. An imbalance in sex over the two treatment groups existed (albeit non-significant) which may have influenced the outcome. We cannot rule out the possibility that a neurohumoral counterregulation could go undetected owing to the small number of patients in our study and the large variation in neurohumoral plasma levels.

\section{CLINICAL IMPLICATIONS}

The aetiology of heart failure is coronary artery disease or hypertension in $60-70 \%$ of cases, ${ }^{26} 27$ and these patients may benefit from the use of additional calcium channel blockers since they lead to both peripheral and coronary vasodilatation..$^{28}$ Both the prevention and the treatment trial of the studies of left ventricular dysfunction (SOLVD) showed that more than $30 \%$ of patients fulfilling the entry criteria were using a calcium channel blocker, ${ }^{129}$ indicating that physicians keep patients on these drugs prescribed for hypertension or coronary artery disease even when symptomatic systolic dysfunction develops. This study in patients with heart failure showed that lacidipine, in conjunction with angiotensin converting enzyme inhibitors, digoxin, and diuretics, improves aerobic capacity, maintains vasodilatation, does not have a major influence on neurohumoral activity, and is generally well tolerated. When a physician considers prescribing a calcium channel blocker to a patient with heart failure-because of hypertension or angina pectoris-second generation calcium antagonists like lacidipine may be preferred to the first generation calcium antagonists. However, with respect to the long term efficacy and safety of second generation dihydropyridines in heart failure, the results of the V-Heft III [evaluating felodipine compared to placebo in addition to diuretics, angiotensin converting enzyme inhibitors, and digoxin], and the Praise study [amlodipine versus placebo in addition to angiotensin converting enzyme inhibitors $]^{14}$ must be awaited.

We express our gratitude to our research nurse Jacqueline Konings for her assistance in the care of the patients and to D er (EUCAM, Clinical Research Organization, Basel, Switzerland) and Dr W Sauermann (DATAMAP, Statistica Analysis, Freiburg, Germany) for data handling and analysis. This study was supported by a grant from Glaxo Verona, Italy.

1 The SOLVD Investigators. Effect of enalapril on survival in patients with reduced left ventricular ejection fractions
and congestive heart failure. $N$ Engl $\mathcal{f}$ Med 1991;325 293-302.
2 Cohn IN. The prevention of heart failure-a new agenda. $N$ Engl F Med 1992;327:725-7.

3 Packer M. Calcium channel blockers in chronic heart failure. The risks of "physiologically rational" therapy. Circulation 1990;82:2254-7.

4 Elkayam U, Amin J, Mehra A, Vasquez J, Weber L, Rahimtoola S. A prospective, randomized, double-blind crossover study to compare the efficacy and safety of chronic nifedipine therapy with that of isosorbide dinitrate and their combination in the treatment of chronic congestive heart failure. Circulation 1990;82:1954-61.

5 Hall ST, Harding SM, Evans GL, Pellegatti M, Rizzini P. Clinical pharmacology of lacidipine. $f$ Cardiovasc Pharmacol 1991;17 suppl 4:9-13.

6 Palatine M, Penzo M, Guzzardi G, Anaclerio M, Pessini A. Ambulatory blood pressure monitoring in the assessment of antihypertensive treatment: 24 hour blood pressure control with lacidipine once a day. $\mathcal{F}$ Hypertens 1991; 9 suppl 3:61-6.

7 Leonetti G. Comparative study of lacidipine and nifedipine SR in the treatment of hypertension: an Italian multicenter study. $\mathcal{f}$ Cardiovasc Pharmacol $1991 ; 17$ suppl 4:31-4

8 Naimark A, Wassermann K, McIlroy MB. Continuous measurement of ventilatory exchange ratio during exercise. $\mathcal{f}$ Appl Physiol 1964;15:644-9.

9 Burrow RD, Strauss HW, Singleton R, et al. Analysis of left ventricular function from multiple gated acquisition cardiac blood pool imaging: comparison to contrast angiography. Circulation 1977;56:1024-8.

10 Westerink BHC. Analysis of trace amounts of catecholamines and related compounds in brain tissue: a study near the detection limit of liquid chromatography with electrochemical detection. $\mathcal{F}$ Chromatogr 1983;6:2337-51.

11 electrochemical detection. F Chromatogr 1983;6:2337-51. Value of New York Heart Association classification, radionuclide ventriculography and cardiopulmonary exerradionuclide ventriculography and cardiopulmonary exercise tests for selection of patients for congest
studies. Am Heart $\mathcal{F} 1988 ; 116: 1475-82$.

12 Kassis A, Amtorp O. Long-term clinical, hemodynamic, angiographic, and neurohumoral response to vasodilation with felodipine in patients with chronic congestive heart with felodipine in patients with chronic conges
failure. $\mathcal{F}$ Cardiovasc Pharmacol 1990;15:347-52.

13 Elkayam U, Shotan A, Mehra A, Ostrzega E. Calcium channel blockers in heart failure. $¥ \mathrm{Am}$ Coll Cardiol 1993; 22(suppl A): 139-44.

14 Schofer J, Hobuss M, Aschenberg W, Tews A. Acute and long-term hemodynamic and neurohumoral response to
nisoldipine vs captopril in patients with heart failure: a nisoldipine vs captopril in patients with heart failure: a
randomized double-blind study. Eur Heart $\mathfrak{f} 1990$; 11:712-21.

15 Dunselman PHJM, Kuntze CEE, van Bruggen A, et al. Efficacy of felodipine in congestive heart failure. Eur Heart f 1989;10:354-64.

16 Tan LB, Murray RG, Littler WA. Felodipine in patients with CHF: discrepant hemodynamic and clinical effects. Br Heart $\mathcal{F}$ 1987;58:122-8.

17 Kassis E, Amtorp O. Cardiovascular and neurohumoral responses to baroreceptor abnormalities during a course of adjunctive vasodilator therapy with felodipine for congestive heart failure. Circulation 1987;75:1204-1213.

18 Cody RJ, Franklin KW, Kluger J, Laragh JH. Sympathetic responsiveness and plasma norepinephrine during therapy of chronic congestive heart failure with captopril. $\mathrm{Am} \mathcal{F}$ Med 1982;72:791-7.

19 Ferguson DW, Berg WJ, Sanders JS, Roach PJ, Kempf JS, Kienzle MG. Sympatho-inhibitory responses to digitalis glycosides in heart failure patients: direct evidence from sympathetic neural recordings. Circulation 1989;80:65-77.

20 Veldhuisen DJ van, Man in 't Veld AJ, Dunselman PHJM, $e$ al. Double-blind placebo-controlled study of ibopamine and digoxin in patients with mild to moderate heart failure: results of the Dutch Ibopamine Multicenter Tria (DIMT). $\mathcal{F} \mathrm{Am}$ Coll Cardiol 1993;22:1564-73.

21 Cohn JN, Rector TS. Prognosis of congestive heart failure and predictors of mortality. Am $\mathcal{F}$ Cardiol 1988;62:25-30A

22 Firth BG, Dehmer GJ, Markham RV, Willerson JT, Hillis LD. Assessment of vasodilator therapy in patients with $\mathrm{LD}$. Assessment of vasodilator therapy in patients with
severe congestive heart failure: limitations of measurements of left ventricular ejection fraction and volumes. $\mathrm{Am}$ ments of left ventricular eject
7 Cardiol 1982;50:954-9.

23 Haq A, Rakowski H, Baigrie R, et al. Vasodilator therapy in refractory congestive heart failure: a comparative analysis refractory congestive heart failure: a comparative analysis
of hemodynamic and non invasive studies. Am $\mathcal{\exists}$ Cardiol of hemodynamic

24 Koolen JJ, van Wezel HB, Piek J, van Liebergen R, Swaan $A$, Visser CA. Effects of intracoronary felodipine versus nifedipine on left ventricular contractility and coronary sinus blood flow in stable angina pectoris. $\mathrm{Am} \mathcal{F}$ Cardiol 1994;74:730-2.

25 Elkayam U, Weber L, McKay C, Rahimtoola S. Spectrum of acute hemodynamic effects of nifedipine in severe congestive heart failure. $A m \mathcal{F}$ Cardiol 1985;56:560 -6.

26 Cohn JN, Johnson G, Ziesche S, et al. A comparison of enalapril with hydralazine-isosorbide dinitrate in the treatment of chronic congestive heart failure. $N \mathrm{Engl} \mathcal{F} \mathrm{Med}$ 1991;325:303-10.

27 Ho KKL, Anderson KM, Kannel WB, Grossman W, Levy $D$. Survival after the onset of congestive heart failure in Framingham heart study subjects. Circulation 1993;88: 107-15.

28 Low RI, Takeda P, Mason DT, DeMaria AN. The effects of calcium channel blocking agents on cardiovascular function. Am ₹ Cardiol 1982;62:669-79.

29 The SOLVD Investigators. Effect of enalapril on mortality and the development of heart failure in asymptomatic patients with reduced left ventricular ejection fractions. $N$ Engl F Med 1992;327:685-91. 